\title{
Perencanaan Peningkatan Pelayanan Sanitasi di Kelurahan Pegirian Surabaya
}

\author{
Zella Nissa Andriani dan Ipung Fitri Purwanti \\ Jurusan Teknik Lingkungan, Fakultas Teknik Sipil dan Perencanaan, Institut Teknologi Sepuluh Nopember (ITS) \\ Jl. Arief Rahman Hakim, Surabaya 60111 Indonesia \\ e-mail:purwanti@enviro.its.ac.id
}

\begin{abstract}
Sanitasi merupakan masalah penting tiap individu dan sangat erat kaitannya dengan kesehatan. Kondisi sanitasi yang kurang baik dapat mengakibatkan masyarakat yang tinggal di lingkungan tersebut mudah terserang penyakit. Kelurahan Pegirian merupakan salah satu wilayah pemukiman padat penduduk dengan kondisi sanitasi yang masih kurang baik terutama di sektor air limbah di Kota Surabaya, sehingga perlu dilakukan peningkatan pelayanan sanitasi dengan merencanakan suatu sistem penyaluran air limbah beserta bangunan pengolahan air limbah. Perencanaan ini menggunakan sistem penyaluran air limbah dengan jenis small bore sewer, sementara untuk bangunan pengolahan air limbah menggunakan Anaerobic Baffled Reactor (ABR) sebagai unit pengolahan air limbah yang memiliki nilai efisiensi yang cukup tinggi untuk mereduksi bahan organik yang terkandung pada air limbah domestik. Dengan adanya perencanaan ini diharapkan dapat meminimalisir terjadinya pencemaran lingkungan dan meningkatkan kondisi sanitasi sehingga tingkat kesehatan masyarakat dapat meningkat.
\end{abstract}

Kata Kunci-Air Limbah Domestik, Anaerobic Baffled Reactor (ABR), Sanitasi, Sistem Penyaluran Air Limbah, Small Bore Sewer

\section{PENDAHULUAN}

$\mathrm{K}$ ELURAHAN Pegirian merupakan satu dari lima kelurahan yang terdapat di Kecamatan Semampir. Kelurahan ini terdiri dari $11 \mathrm{RW}$ dan $95 \mathrm{RT}$. Berdasarkan data yang diperoleh dari Dinas Kesehatan Kota Surabaya tahun 2014 [1], keadaan sanitasi di Kelurahan Pegirian masih tergolong rendah. Kondisi sanitasi yang kurang baik ini mengakibatkan masyarakat mudah terserang penyakit [2]. Hal ini didukung berdasarkan data dari Puskesmas Pegirian yang menyebutkan bahwa sepanjang tahun 2013 tercatat sebanyak $70 \%$ penduduk di Kelurahan Pegirian terkena penyakit diare. Penyakit diare merupakan salah satu indikator buruknya kondisi sanitasi suatu lingkungan [3].

Pencegahan terhadap jenis-jenis penyakit lain akibat sanitasi yang buruk dapat dilakukan dengan penanganan yang baik dan seksama sehingga tercipta kondisi lingkungan yang baik dan pencemaran pun dapat dicegah. Salah satu upaya untuk mencapai lingkungan yang sehat yaitu dengan dibangunnya suatu bangunan pengolahan air limbah secara komunal untuk meningkatkan akses layanan sanitasi air limbah, terutama di pemukiman yang padat penduduk dan berpenghasilan rendah [4].
Setelah melakukan observasi lapangan dan wawancara terhadap beberapa warga, diketahui bahwa beberapa RW di Kelurahan Pegirian meski sebagian besar sudah memiliki tangki septik, namun masih belum memiliki fasilitas penyaluran air limbah maupun bangunan pengolahan air limbah secara komunal sehingga air limbah grey water langsung dibuang menuju ke selokan tanpa melalui proses pengolahan sehingga sering menimbulkan masalah pada lingkungan.

Timbulnya masalah pada lingkungan akan menyebabkan penurunan kualitas lingkungan dan tingkat kesehatan masyarakat yang tinggal di sekitar lingkungan tersebut, sehingga diperlukan suatu penanganan air limbah yang baik dan terpadu baik dalam penyaluran maupun pengolahannya untuk mengurangi semaksimal mungkin terjadinya pencemaran lingkungan. Melihat pentingnya suatu sistem penyaluran dan pengolahan air limbah, sehingga diperlukan suatu kajian secara teknis berkaitan dengan peningkatan akses pelayanan sanitasi air limbah di wilayah Kelurahan Pegirian. Kajian secara teknis ini terangkum dalam suatu perencanaan peningkatan akses pelayanan sanitasi dengan mempertimbangkan berbagai faktor yang mungkin ditemui di Kelurahan Pegirian.

Wilayah studi pada perencanaan ini berada di RW 1 dan 2 Kelurahan Pegirian, Kecamatan Semampir, Surabaya Utara. Perencanaan sanitasi ini hanya mencakup bidang air limbah saja yaitu meliputi sistem penyaluran air limbah (SPAL) dan pengolahan air limbah domestik (IPAL). Aspek yang ditinjau yaitu aspek teknis dengan menggunakan beberapa data primer seperti hasil pengamatan kondisi lahan, hasil wawancara dan kuisioner, serta karakteristik air limbah di Kelurahan Pegirian Surabaya.

\section{METODE PERENCANAAN}

Tahap perencanaan merupakan penjelasan mengenai tahap demi tahap perencanaan yang telah disusun pada kerangka perencanaan. Tahap perencanaan meliputi judul perencanaan, studi pustaka, pengumpulan data, hasil pembahasan, kesimpulan dan saran. Gambar 1 menunjukkan tahapan perencanaan: 


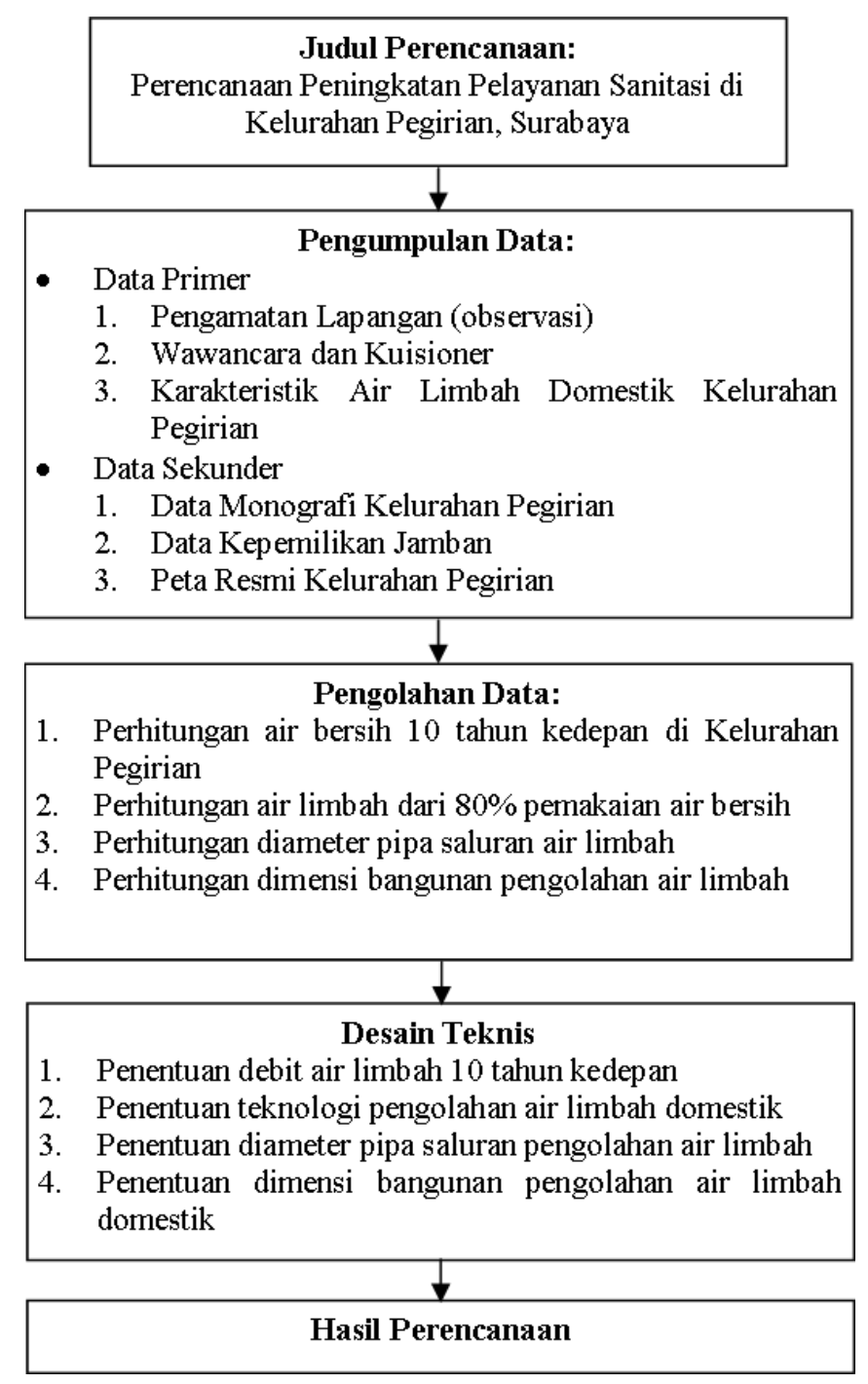

Gambar 1 Tahap Perencanaan

\section{HASIL DAN PEMBAHASAN}

\section{A. Perhitungan Debit Air Limbah}

Perencanaan ini menggunakan proyeksi penduduk 10 tahun kedepan. Hal ini bertujuan agar bangunan saluran dan pengolahan air limbah berfungsi dengan baik sesuai kapasitasnya. Air limbah yang akan diolah di instalasi pengolahan air limbah dihitung berdasarkan debit air bersih yang dibutuhkan dalam kegiatan sehari-hari. Berdasarkan kuisioner yang telah disebar ke beberapa warga di RW 1 dan 2 Kelurahan Pegirian, dapat diketahui bahwa debit air bersih per orang sebanyak 120 liter per detik atau setara dengan $18 \mathrm{~m}^{3}$ per detik Hasil kuisioner juga menyebutkan bahwa sekitar $80 \%$ dari kebutuhan air bersih akan menjadi air limbah.

Untuk menghitung debit air limbah di RW 1 dan 2, wilayah studi dibagi menjadi beberapa bagian wilayah untuk kemudian dibuat blok pelayanan agar memudahkan dalam menentukan dimensi saluran air limbah dan juga memperingan pembebanan saluran air limbah. Adapun blok pelayanan di RW 1 dan 2 Kelurahan Pegirian disajikan pada Gambar 2.

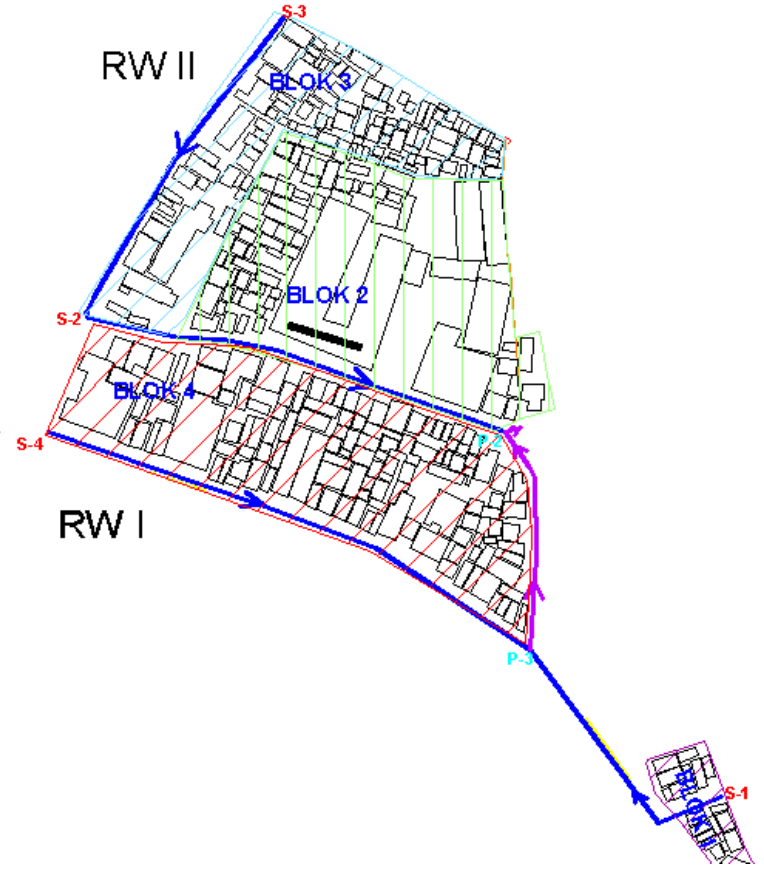

Gambar 2 Blok Pelayanan di RW 1 dan 2

Berdasarkan Gambar 2, blok pelayanan 1 merupakan wilayah yang diarsir warna ungu dengan luas area pelayanan sebesar 3,12 ha, blok pelayanan 2 merupakan wilayah yang diarsir warna hijau dengan luas area pelayanan sebesar 16,93 ha, blok pelayanan 3 merupakan wilayah yang diarsir warna biru dengan luas area pelayanan sebesar 5,57 ha, dan blok pelayanan 4 merupakan wilayah yang diarsir warna merah dengan luas area pelayanan sebesar 15,42 ha.

Debit air limbah yang merupakan $80 \%$ dari debit air bersih di jalur S1-P3 yang ditunjukkan pada Gambar 2 sebesar $0,0001 \mathrm{~m}^{3} /$ detik. Berdasarkan Gambar 3, diketahui bahwa faktor puncak dari debit air limbah di jalur tersebut sebesar 3,3 sehingga dapat ditentukan besarnya debit puncak di jalur S1P3 tersebut sebesar 0,00014 m3/detik.

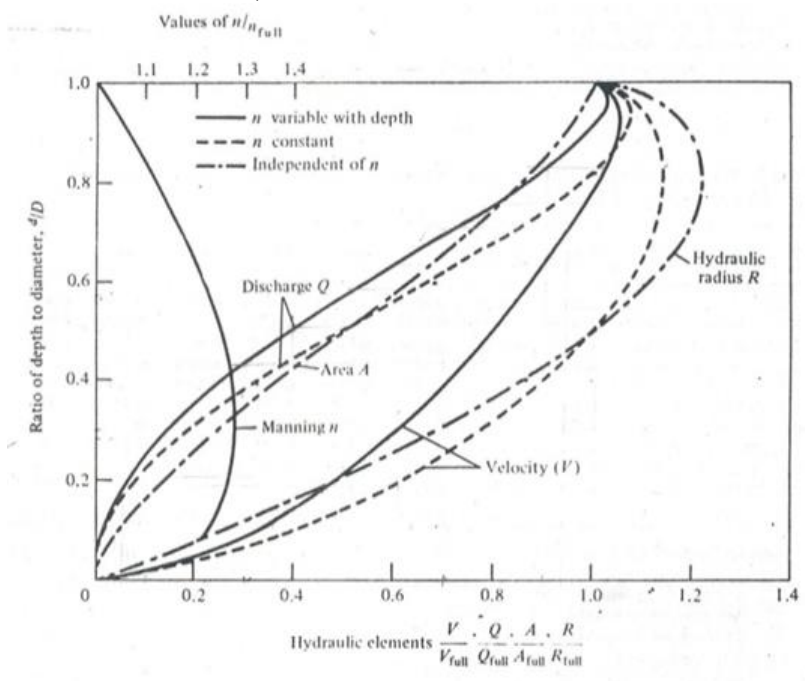

Gambar 3 Hidrolik Pada Saluran Air Limbah

Berdasarkan Gambar 4, dapat diketahui bahwa dengan luas wilayah sepanjang jalur S1-P3 seluas 15,47 ha memiliki faktor 
infiltrasi sebesar 15 , sehingga didapatkan debit infiltrasi sebesar $0,0021 \mathrm{~m}^{3} /$ detik. Sedangkan untuk debit minimum di jalur tersebut adalah $0,000002 \mathrm{~m}^{3} /$ detik.

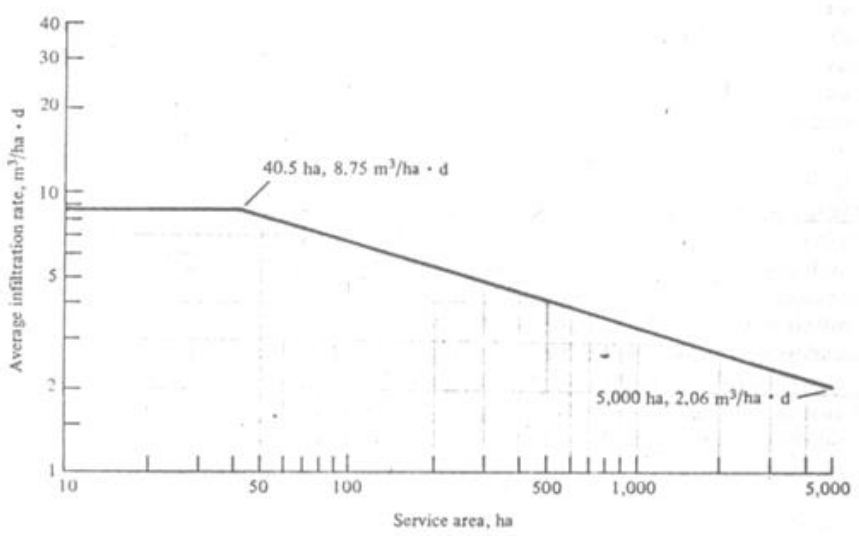

Gambar 4 Faktor Infiltrasi

\section{B. Diameter Pipa Sistem Penyaluran Air Limbah}

Perhitungan dimensi sistem penyaluran air limbah didasarkan pada kebutuhan akan penyaluran dan bangunan pengolahan air limbah sampai pada akhir periode desain yang direncanakan. Batasan-batasan yang dijadikan pedoman dalam merencanakan diameter saluran air limbah antara lain:

- Kecepatan maksimum dalam pipa tidak melebihi 2,5 m/dt.

- Kecepatan minimum dalam pipa tidak kurang dari 0,3 m/dt.

- Tinggi renang minimum $50 \mathrm{~mm}$

- Tinggi renang pada saat debit maksimum (Qfull) antara $60 \%$ sampai $80 \%$ dari diameter pipa.

Diameter pipa sistem penyaluran air limbah dapat dilakukan dengan menetapkan nilai d/D dengan menggunakan Gambar 3 untuk kemudian didapatkan nilai Qpeak/Qfull. Pada perencanaan ini, direncanakan nilai d/D pada pipa di jalur S1P3 adalah 0,8. Kemudian dengan menggunakan Gambar 3 didapatkan nilai Qpeak/Qfull sebesar 0,975 sehingga dapat diketahui besarnya Qfull pada pipa S1-P3 yang ditunjukkan pada Gambar 5 adalah $0,00014 \mathrm{~m}^{3} /$ detik.

Pada perencanaan ini, digunakan slope rencana karena elevasi tanah di beberapa titik memiliki ketinggian yang sama. Slope rencana yang digunakan yaitu sebesar $1 \%$. Setelah diketahui besarnya Qfull dan slope yang digunakan, maka dapat ditentukan bahwa diameter pipa pada saluran S1-P3 sebesar 25,97 $\mathrm{mm}$ dan sesuai yang ada di pasaran, maka diameter pipa yang digunakan adalah $100 \mathrm{~mm}$.

Setelah mendapatkan besarnya diameter pipa saluran, dapat diketahui besarnya kecepatan maksimum pada saat kondisi pipa dalam keadaan penuh yaitu sebesar $0,7 \mathrm{~m} /$ detik. Kecepatan maksimum yang diperbolehkan adalah tidak lebih dari 2,5 $\mathrm{m} /$ detik karena dikhawatirkan dapat menyebabkan terjadinya penggerusan terhadap saluran. Sementara kecepatan minimum pada pipa yaitu sebesar $0,5 \mathrm{~m} /$ detik.

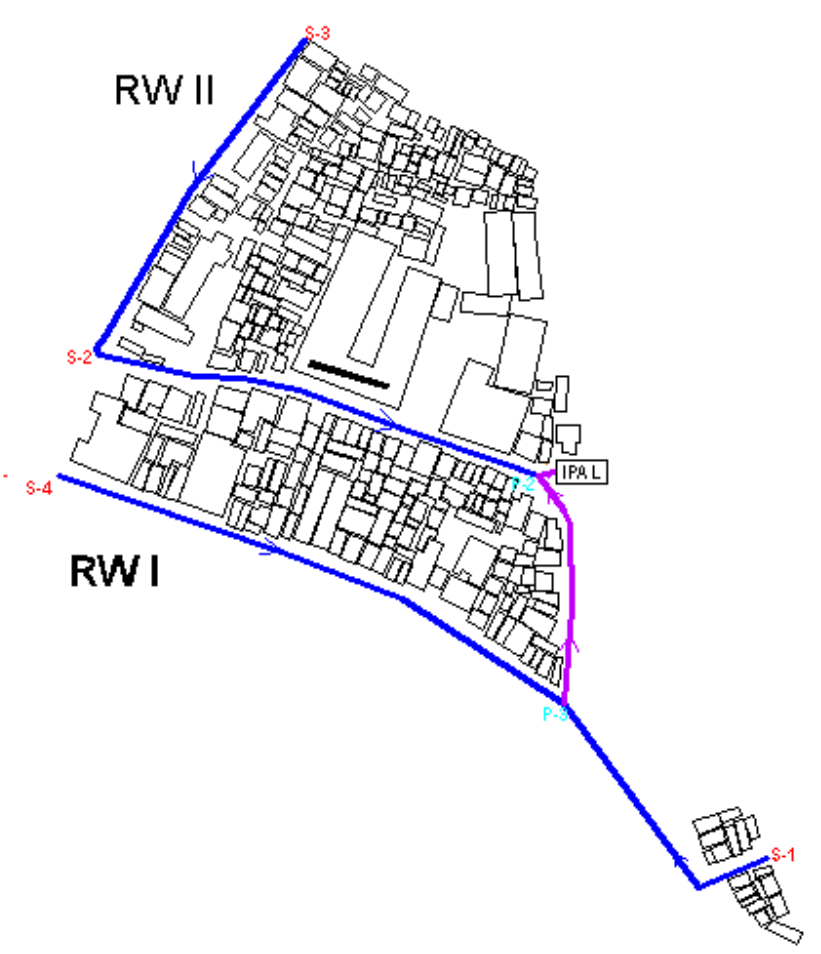

Gambar 5 Jalur Pipa di RW 1 dan 2

\section{Penanaman Saluran Air Limbah}

Penanaman pipa disesuaikan dengan kemiringan saluran yang telah diperhitungkan agar air limbah dapat mengalir secara gravitasi. Elevasi tanah di titik S1 maupun P3 yaitu 6 meter. Sehingga dapat diketahui bahwa selisih kemiringan antara titik S1 dan P3 adalah 0. Hal ini menunjukkan bahwa pipa di jalur S1 dan P3 membutuhkan slope perencanaan agar air limbah dapat mengalir secara gravitasi.

Kedalaman penanaman pipa awal jenis sekunder dan tersier adalah 0,5 meter. Hal ini dikarenakan, kedalaman pipa primer harus lebih rendah dari pipa sekunder dan tersier agar aliran air limbah dapat terjadi secara gravitasi. Sehingga dapat diketahui elevasi atas pipa awal setinggi 5,5 meter sementara elevasi atas pipa akhir yang terletak di titik P3 setinggi 4,4 meter.

Kedalaman penanaman pipa minimal harus disesuaikan dengan kondisi yang dilewati saluran, jenis tanah, lokasi bangunan, kekuatan dan diameter saluran. Umumnya, kedalaman minimum saluran adalah 1 meter, sedangkan kedalaman maksimum adalah 7 meter. Jika penanaman lebih dari 7 meter, maka harus menggunakan pompa.

Pada perencanaan ini, kedalaman penanaman pipa awal yang terletak di titik S1 yaitu sedalam 0,8 meter dari elevasi tanah awal. Sementara untuk kedalaman penanaman pipa akhir yang terletak dititik P3 yaitu sedalam 1,9 meter.

\section{D.Manhole}

Manhole merupakan bangunan pelengkap pada sistem penyaluran air limbah yang berbentuk lubang yang digunakan untuk memeriksa, memelihara dan memperbaiki saluran. Jarak antar tiap manhole lurus pada perencanaan ini yaitu 150 meter sehingga dapat diketahui jumlah manhole lurus yang 
dibutuhkan sebanyak 1 buah dan manhole belokan sebanyak 1 buah

\section{E. Profil Hidrolis}

Saluran U tama
Profil hidrolis merupakan titik letak penanaman yang harus digali pada saat konstruksi dan peletakan serta kebutuhan bangunan pelengkap. Gambar 6 menunjukkan profil hidrolis di RW 1 dan 2 Kelurahan Pegirian.

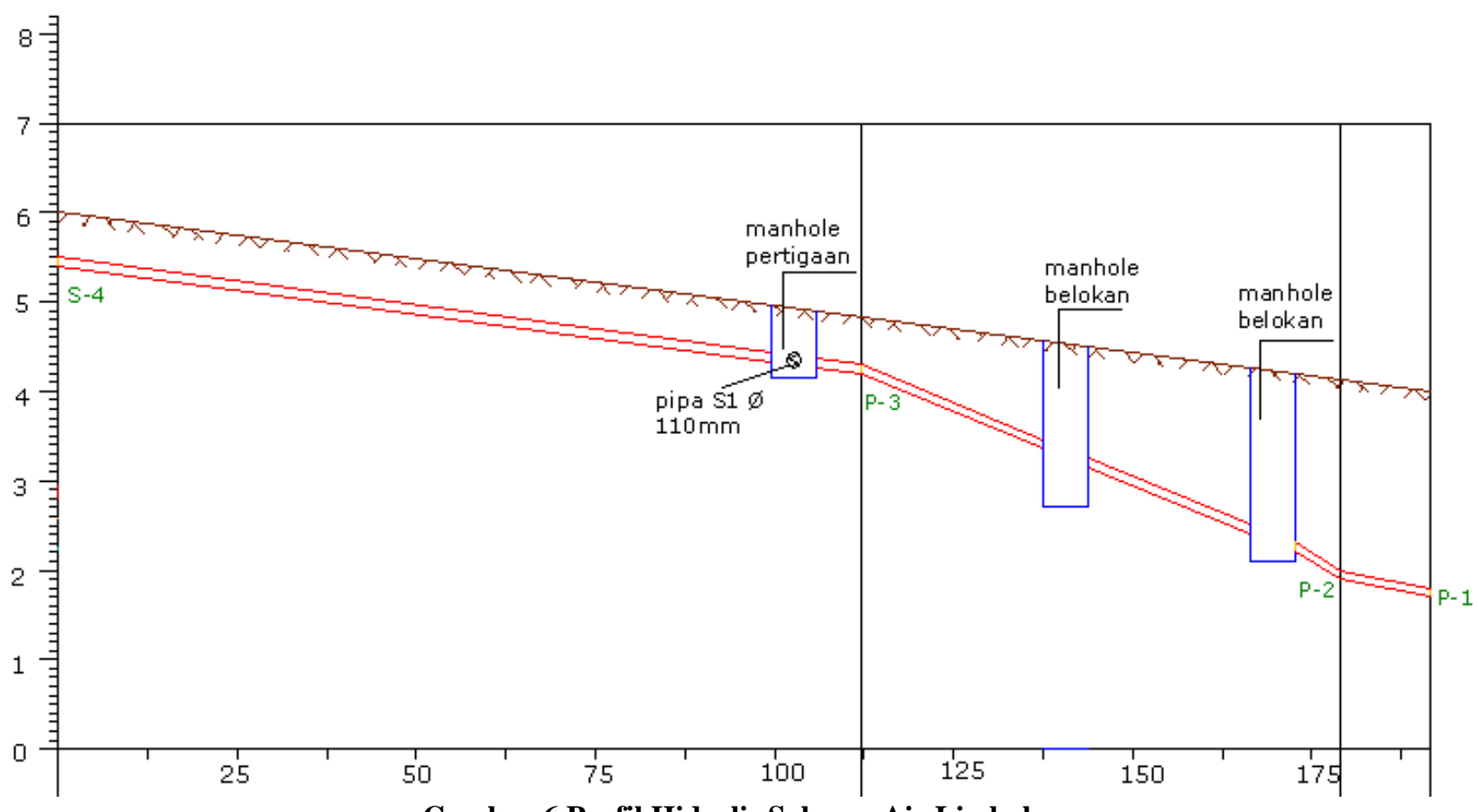

Gambar 6 Profil Hidrolis Saluran Air Limbah

\section{F. Instalasi Pengolahan Air Limbah Domestik}

Perencanaan ini menggunakan Anaerobic Baffled Reactor (ABR) karena tingginya efisiensi removal dari bangunan ABR terhadap zat organik, sehingga kualitas hasil tidak mencemari badan air.

Adapun karakteristik air limbah domestik di Kelurahan Pegirian berdasarkan hasil analisa laboratorium kualitas lingkungan jurusan Teknik Lingkungan ITS yaitu:

BOD $=232 \mathrm{mg} / \mathrm{L}$

$\mathrm{COD}=380 \mathrm{mg} / \mathrm{L}$

TSS $=256 \mathrm{mg} / \mathrm{L}$

Tahapan proses pengolahan air limbah pada perencanaan ini digambarkan melalui bagan alir proses. Bagan alir pengolahan air limbah pada perencanaan ini disajikan dalam Gambar 5 sebagai berikut:

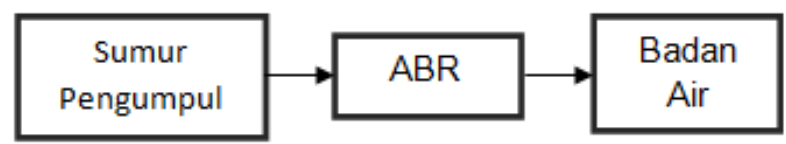

Gambar 7 Bagan Alir Proses Pengolahan Air Limbah

\section{Sumur Pengumpul}

Pada perencanaan ini, sumur pengumpul direncanakan berbentuk segi empat sebanyak 1 buah dengan kedalaman 2 meter, panjang 1,5 meter dan lebar 1 meter. Sumur pengumpul ini juga dilengkapi dengan pompa untuk memompa air limbah menuju bangunan $\mathrm{ABR}$.

\section{Anaerobic Baffled Reactor (ABR)}

Perencanaan ini menggunakan sumber dari BORDA, Sasse, L (1998) [5] dalam menentukan dimensi bangunan ABR. Berdasarkan karakteristik air limbah yang di Kelurahan Pegirian, diketahui bahwa rasio COD/BOD sebesar 1,64 dengan rasio SS/COD sebesar 0,4.

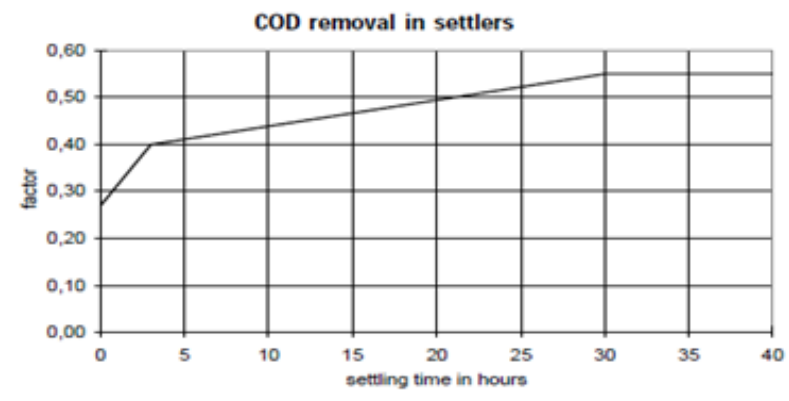

Gambar 8 Hubungan COD removal dan HRT

Efisiensi removal COD di Tangki Septik didapatkan dengan menggunakan Gambar 8 sehingga dapat diketahui efisiensi removal COD yang terjadi di tangki septik bangunan ABR ini sebesar $23 \%$. 
Untuk mendapatkan efisiensi removal $\mathrm{BOD}_{5}$ di tangki septik, perlu diketahui faktor removal COD/BOD yang didapatkan dengan Gambar 9 sehingga didapatkan nilai 1,06. Setelah mengetahui nilai faktor removal COD/BOD, maka efisiensi removal $\mathrm{BOD}_{5}$ di tangki septik dapat diketahui yaitu sebesar $25 \%$.

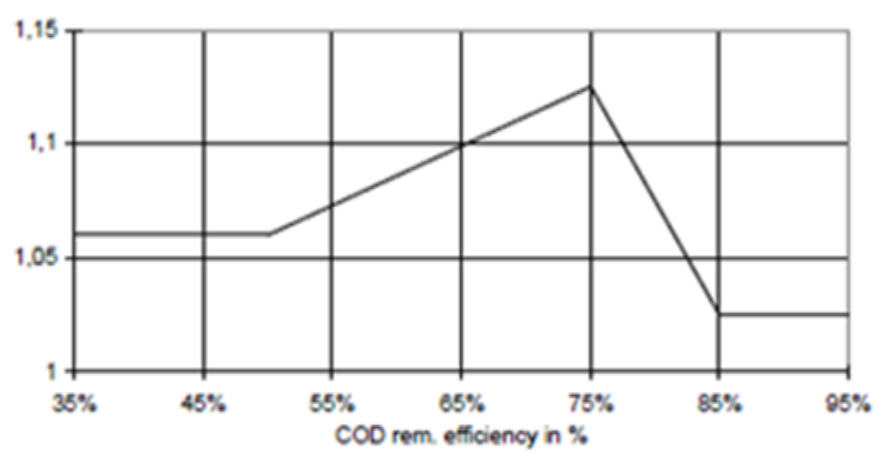

Gambar 9 Faktor Removal COD/BOD

Dengan mengetahui efisiensi removal COD dan BOD setelah melewati proses pengendapan di tangki septik, maka dapat diketahui konsentrasi COD dan BOD yang masuk ke bak selanjutnya atau baffled reactor. Konsentrasi COD yang masuk ke baffled reactor sebanyak $291,33 \mathrm{mg} / \mathrm{L}$ sementara konsentrasi BOD yang masuk ke baffled reactor sebanyak 232 $\mathrm{mg} / \mathrm{L}$.

Untuk mendapatkan nilai efisiensi removal COD di baffled reactor, perlu diketahui nilai beberapa faktor seperti faktor overload, faktor strength, faktor suhu, faktor HRT

Nilai overload factor didapatkan dengan menggunakan grafik persamaan antara banyaknya BOD yang akan diolah (Organic Loading Rate) dengan faktor overload pada Gambar 10. Jumlah BOD yang masuk ke Baffled Reactor sebanyak $0,47 \mathrm{~kg} \mathrm{BOD} / \mathrm{m}^{3}$ hari, sehingga didapatkan nilai overload factor adalah 1 .

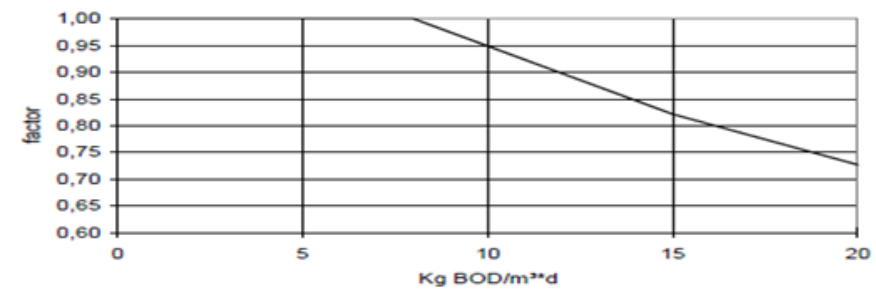

Gambar 10 Persamaan OLR dan overload factor

Jumlah BOD yang masuk ke baffled reactor untuk diolah, berpengaruh terhadap kekuatan air limbah yang nantinya akan mempengaruhi efisiensi removal BOD di baffled reactor. Untuk mendapatkan nilai kekuatan air limbah (strength factor), digunakan grafik persamaan antara BOD removal di baffled reactor dengan faktor kekuatan air limbah pada Gambar 11 sehingga didapatkan bahwa nilai strength factor adalah 0,8 .

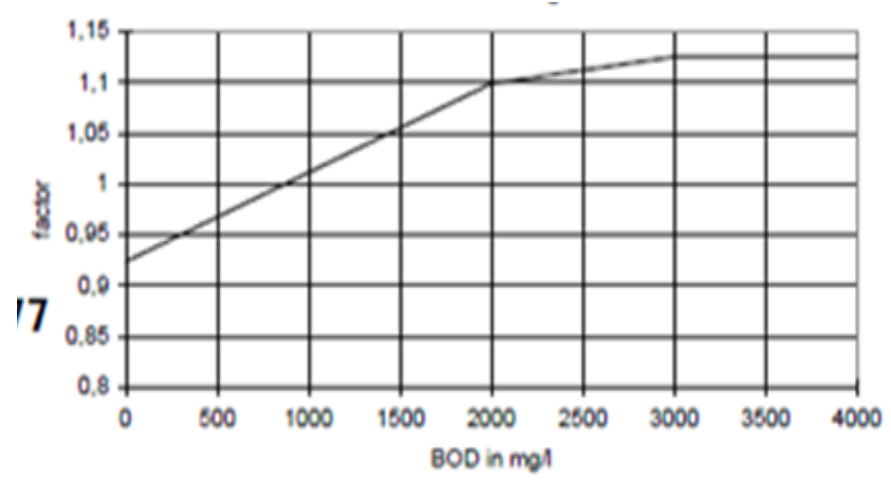

Gambar 11 BOD removal di baffled reactor berhubungan dengan kekuatan air limbah

Suhu juga merupakan salah satu faktor yang berkaitan dengan efisiensi COD removal pada reaktor anaerobik. Untuk mendapatkan nilai temperature factor, digunakan Gambar 12 . Pada perencanaan ini, suhu reaktor adalah $30^{\circ} \mathrm{C}$ sehingga didapatkan nilai faktor suhu adalah 1,05.

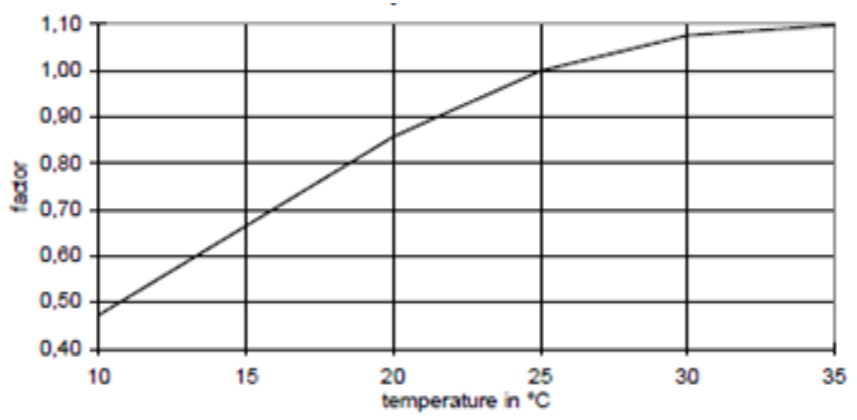

Gambar 12 COD Removal Berhubungan Dengan suhu Reaktor Anaerobik

Banyaknya kompartemen pada reaktor anaerobik berpengaruh terhadap faktor waktu detensi. Jumlah kompartemen yang digunakan pada perencanaan ini sebanyak 5 buah, sehingga nilai HRT faktor adalah 1,02.

Setelah mendapatkan nilai dari beberapa faktor, dapat diketahui besarnya COD removal yang terjadi di baffled reactor yaitu $84 \%$ sehingga konsentrasi COD yang keluar dari bangunan ABR tersebut sebanyak $45 \mathrm{mg} / \mathrm{L}$. Sementara efisiensi removal $\mathrm{BOD}_{5}$ di baffled reactor diketahui sebesar 90\% sehingga konsentrasi $\mathrm{BOD}_{5}$ yang keluar dari bangunan ABR sebanyak $17 \mathrm{mg} / \mathrm{L}$.

Setelah memastikan efisiensi removal COD dan BOD sudah sesuai dengan kriteria perencanaan, dimensi bangunan $A B R$ dapat mulai ditentukan. Pada perencanaan ini, bangunan ABR direncanakan terdiri dari 5 buah kompartemen yang masingmasingnya memiliki kedalaman 1,83 meter dengan panjang 1 meter dan lebar 2 meter seperti pada Gambar 13. 


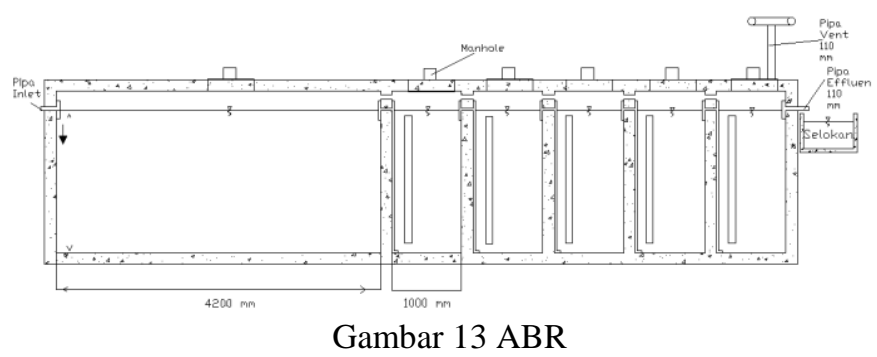

\section{KESIMPULAN/RINGKASAN}

Perencanaan SPAL dan IPAL ini berada di RW 1 dan 2 Kelurahan Pegirian, Kecamatan Semampir, Kota Surabaya. Perencanaan SPAL membutuhkan panjang pipa sebesar 554 meter dan diameter sebesar $100 \mathrm{~mm}$. Perencanaan SPAL ini dilengkapi dengan bangunan manhole lurus sebanyak 5 buah dan manhole belokan sebanyak 2 buah yang memiliki kedalaman mencapai 2 meter.

Perencanaan IPAL menggunakan bangunan Anaerobic Baffled Reactor sebanyak 1 unit yang terdiri dari 5 kompartemen yang masing-masingnya memiliki dimensi bangunan dengan kedalaman 1,83 meter, panjang 1 meter dan lebar 2 meter. Bangunan ABR ini memiliki kemampuan removal sebesar $88 \%$ dan HRT selama 2 jam.

\section{DAFTAR PUSTAKA}

[1] Harmayani,K.D dan Konsukartha, I.G.M. 2007, Pencemaran Air Tanah Akibat Pembuangan Limbah Domestik Di Lingkungan Kumuh. Denpasar: Universitas Udayana

[2] Sri Subekti, 2009, Pengelolaan Limbah Cair Rumah Tangga. Semarang: Tugas Akhir Program Sarjana Fakultas Teknik Lingkungan Universitas Pandanaran

[3] Direktorat Jenderal Cipta Karya, 2014, Buku Petunjuk Praktis MPS (Memorandum Program Sanitasi). Jakarta: Kementrian Pekerjaan Umum

[4] Sasse, L, 1998, Decentralised Wastewater Treatment in Developing Countries. Jerman: BORDA 